Igor Lakić ${ }^{1}$

DOI: 10.31902/LL.2019.7.2

\title{
EVALUATIVE ASPECTS OF PRINT MEDIA TEXTS
}

\begin{abstract}
This paper revisits the concept of macrostructure, i.e. the thematic and organizational structure of texts, in this case that of the news discourse and its link with Critical Discourse analysis (CDA). Special focus is put on the Evaluation as a part of the news story macrostructure. The paper presents the author's model of news structure in print media, based on the models of van Dijk (1988a, 1988b) and Bell (1994). The following parts of the macrostructure are identified: (1) Headline, (2) Lead, (3) Main Event(s), (4) Background of the Event, (5) Verbal Comment(s), (6) Evaluation, and (7) Results of the Event. The author also points out that pure linguistic analysis itself cannot lead to proper interpretation of news discourse. Based on these two aspects, the paper specifically focuses on Evaluation as a part of the macro structure and its linguistic exponents on the microstructure level. Evaluation includes attitudes, opinions or the evaluation of the event by the journalist or the newspaper he/she writes for. It is the Evaluation that gives sense or meaning to the text. Evaluation will be discussed in terms of its explicit presence in the text, as a distinctive unit in the schematic structure of news, but also in its implicit form, very often hidden behind other parts of macrostructure such as Headline, Lead, Main Event or Verbal Comments. The examples of Evaluation will be taken from a corpus comprising examples from three British and three Montenegrin dailies reporting on the NATO airstrikes against former Yugoslavia.
\end{abstract}

Key words: evaluation, discourse analysis, macrostructures, microstructures, CDA

\section{Introduction}

Media shape the world around, influencing our opinions and conclusions on the context in which we live. These views are always dependent on different aspects, such as political orientation, interests of the media owners, advertisers etc. In the times of crises, the tendency of the media to shape their readers'/viewers' opinions is particularly evident. Such situations lead media to present events from a specific, sometimes biased point of view, in order to attract the attention and trust of their readers or viewers for a specific cause. Media's evaluation of events is therefore crucial in shaping public opinion.

Martin and White (2005: 1) refer to evaluation as a "subjective presence of writers/speakers in texts as they adopt stances towards both the material they present and those with whom they communicate".

Bednarek (2006: 4) claims that evaluation occupies a significant place in our lives through which we interpret the world around us and offer this evaluation to others. It also determines our behaviour. In such a way, our short-term evaluations may become long-term values which determine our personality, the way of life, the friendships we make, etc. She also adds that "... evaluation is extremely important in actual discourse, in that it is difficult if not impossible for human beings (and perhaps not even desirable) to speak with a completely 'objective' voice, not to impose evaluations on one's utterance, and not to communicate value judgements" (Bednarek: 2006: 5).

${ }^{1}$ Associate professor at the University of Montenegro. 
In addition, Martin and White (2005:92) claim that "all utterances are seen as in some way stanced or attitudinal". This means that even an attempt to be neutral and impartial can still have a hint of a biased stance, although unintentional.

This paper is based on a more comprehensive analysis (Lakić, 2011) of selected examples from three British dailies (the Guardian, the Independent and the Times) on NATO airstrikes on Yugoslavia. Quantitative analysis is not presented here due to the limited space and the scope of the paper, but our findings are certainly based on linguistic evidence. The purpose of this paper is therefore to show the evaluative force of media text from the qualitative point of view in combination with the analysis of the units on the micro level. Different ideas are certainly expressed through linguistic means, such as words or phrases, but the impact of these ideas is seen much more on the metalinguistic rather than purely linguistic level.

After the introduction, the paper first offers some theoretical insights into the topic of evaluation as a part of the macrostructure of news story. The next chapter presents and discusses examples of evaluation in the selected corpus. The paper ends with conclusions.

\section{Theoretical framework}

News story, just like any other story, has its constituent parts. The theory of 'news schemata' developed by van Dijk deals with the organisational pattern of news in print media and the linguistic analysis of texts. Van Dijk (1988a: 51) distinguishes between macrostructure (functional units or thematic and organisational structures of texts) and microstructure (linguistic aspects of texts such as syntax, vocabulary, cohesive devices, etc.).

Van Dijk (1988a, 1988b) and Bell (1994) provided their own models of the organisational pattern of news. The two models are quite similar, although the terminology used does not fully overlap. For the purpose of my analysis, I developed my own model of the organisational pattern of the analysed texts, using the terminology that best reflected the purpose of my research. The model (Lakić, 2011: 52 ) is as follows:

\section{Headline}

2. Lead (summarising the main event)

3. Main event (elaboration of the news mentioned in the lead)

4. Background of the event (who, how, where and when)

5. Verbal comment (of the most important participants in the event)

6. Evaluation (attitudes, expectations and evaluation of the event by the journalist)

7. Results of the event (why the event is important and how serious its consequences are).

Evaluation, as a part of this macrostructure, is the functional unit in which journalists express their attitudes, opinions and evaluation of the event(s). Many believe that facts and personal opinions should not be mixed (van Dijk, 1988a: 56), 
but this category is still very much present in the news, directly or indirectly. This part is actually important because it gives a meaning to the story and contributes to its coherence.

Evaluation, also known as appraisal or stance, is "... a category that features the comments, opinions and evaluations of the journalist or newspaper itself" (van Dijk, 1988a: 56).

Thompson and Hunston (2000: 5) define evaluation in the following way:

„... the broad cover term for the expression of the speaker's or writer's attitude or stance towards, viewpoint on, or feelings about the entities or propositions that he or she is talking about. That attitude may relate to certainty or obligation or desirability or any of a number of other sets of values."

These sets of values are referred to as evaluation parameters (Bednarek, 2006: 3-4). Bednarek assumes that speakers can evaluate aspects of the world as:

- good or bad (the parameter of EMOTIVITY),

- important or unimportant (the parameter of IMPORTANCE),

- expected or unexpected (the parameter of EXPTECTEDNESS),

- comprehensible or incomprehensible (the parameter of COMPREHENSIBILITY),

- (not) possible or (not) necessary (the parameter of POSSIBILITY),

- genuine or fake (the parameter of RELIABILITY).

She also suggests that speakers may evaluate propositions as:

- more or less reliable (RELIABILITY: LOW/MEDIAN/HIGH), and

- that they can make evaluative comments on the language that is used (the parameter of STYLE),

- on other social actors' mental states (the parameter of MENTAL STATE), and

- on the source of their knowledge (the parameter of EVIDENTIALITY).

At the time of war, it can be assumed that readers evaluate news based on the parameters of emotivity and reliability, although the first parameter is probably the most prominent one, bearing in mind the impact of war on readers' life. Reliability is also crucial in evaluating propositions.

Bednaek (2006: 8) claims that evaluation can be correctly understood, interpreted and analysed only from the context, adding that linguistic means of evaluation are context-dependent to a large extent and that evaluation "extend like a wave over the text and lends a specific 'evaluative prosody' to it".

Bednarek (2006: 8) adds that such an analysis would not only pick up instances of writer evaluation but also instances where evaluation is simply quoted. She also claims that there is no clearly-defined list of linguistic means of evaluation (the co-called evaluators) that could be looked for in a large-scale corpus with the help of a computer, while an endless list of lexico-grammatical means used to 
express evaluation would lead to a complicated and lengthy list of evaluators in a large corpus.

This raises the question of the possibility to identify evaluation only on the basis of overt linguistic means. This can hardly be the case, since the linguistic means used to express evaluation can be endless and hard to cope with.

Arrese , Begoň and Perucha (2006: 226) say that "news is characterized by the presence of expressions of attribution, whereby the writer acknowledges or distances him/herself from the viewpoints and assessments attributed to external voices". They propose patterning of various linguistic resources. They analyse text taking into account engagement, writer's stance and (inter)subjectivity. According to them, engagement includes not only the evaluative language means by which a writer or a speaker adopts a particular position or stance, but also the elements by which they interact with their potential or real audience - readers or hearers. These linguistic means are mainly evidentiality, modality or hedging (Arrse, Begoň and Perucha, 2006: 227-228).

Again, the question is whether it is really possible to define clear-cut patterns and language means based on which it is possible to deal with evaluation. Martin (2003: 177) claims that the function of evaluation in a culture cannot be understood if our studies are based, however quantitatively, on the analysis of "decotextualized" examples, while Stotesbury (2003: 331) proposes that it is not possible to notice the evaluative force of linguistic expressions in an automatic corpus-based study.

Looking from the perspective of our analysis, there are certainly linguistic means that point to evaluation and they can be identified quite easily, even without making a list of language units, which, no matter how extensive, can be limiting. Each text has its own rationale and ideas and each can, as a result, offer different units on the microlevel to express evaluation of events. On the other hand, without these linguistic units, it can be hardly possible to interpret the text, as such an analysis could easily slip into subjectivity. That is why a combination of the two is the best way.

This is certainly where the Critical Discourse Analysis (CDA) has a crucial role. CDA goes beyond pure linguistic analysis and aims at using linguistic findings in order to interpret events in a certain way, taking into consideration social and other indicators that lie outside linguistics. This is why this approach is also referred toas a socio-political discourse analysis.

Fairclough (1996: 311-13) proposes three dimensions of the linguistic analysis of news: text, discursive practice and social practice. While text analysis offers just formal characteristics of texts including both form and meaning, discursive practice deals with the production, consumption and distribution of discourse under study. Constant and quick changes in our societies lead to changes in the discursive practice of the media. The third dimension, social practice, refers to the analysis of social and cultural events, such as the study of the political context of events and how ideology influences and contributes to social changes. This allows linguists to put any text in a certain social context.

Fairclough (1996: 314-15) also discusses the distinction between linguistic analysis and intertextual analysis of texts. According to him, linguistic analysis is 
more descriptive in nature, while intertextual analysis is more interpretative and it analyses the text from the point of view of discourse practice. Fairclough advocated a connection of linguistic analysis and intertextual analysis in order to overcome the gap between text on the one hand and society and culture on the other.

However, another question comes up here. Is evaluation always so explicit that linguistic units on the micro level clearly point to its existence? My analysis has shown that evaluation, in addition to being explicit, can be also implicit. Little attention in literature has been paid to the implicit presence of evaluation in the news. Still, van Dijk (1988: 56) provides such a possibility: "Although many newsmakers share the ideological view that fact and opinion should not be mixed, the final Comments category frequently appears in the news, albeit sometimes in an indirect form." ${ }^{2}$

The literature on structuring information in news texts usually describes these parts as separate entities, although my research (Lakić, 2011) shows that a clear line between them cannot always be drawn. I have identified three possible instances of these combinations as a result of my research:

(1) Two parts of a macrostructure are combined into one sentence or a shorter paragraph, where both parts are given equal importance.

(2) One part of a macrostructure is embedded into another, whereby the embedded part is usually shorter and of less formal importance, although it can cause a change in the point of view expressed in the text.

(3) A certain part of the text can be interpreted in two ways. For example, Headlines may often express attitudes of journalists. In such a situation, Headline can be interpreted as an Evaluation at the same time. My research shows that this is especially true for Evaluation, probably because in wartime journalists try to avoid expressing their opinions openly. Instead, they express their ideas in a less direct form, mainly through Headlines, Leads or Verbal Comments.

While the possibilities (1) and (2) are examples of somewhat explicit evaluation, although not always very visible, because linguistic units clearly point to the explicit nature of evaluation, the third possibility clearly points to an implicit (indirect) evaluation.

These elements are identified on the basis of their functions within a text, but also bearing in mind the linguistic aspects such as lexis, syntax, semantics, discourse markers etc. In the next part we will pay attention to these possibilities.

\section{Analysis}

When it comes to the explicit presence of evaluation in the analysed papers, it is possible to identify such cases, although they do not prevail among all the instances of evaluation found in the analysed texts. Let us consider the following example:

"With refugee crisis worsening, NATO governments are under increasing pressure to show that the air bombardment is having results on the ground." (G, Apr 3)

\footnotetext{
2 Van Dijk uses here the term Comments for what I label as Evaluation, while the adjective indirect stands for my term implicit.
} 
Here, evaluation is obvious, as the author expresses their opinion about the NATO action. The author's claim that NATO governments are under increasing pressure to show that bombardment is giving results on the ground is actually a criticism of NATO, especially in the light of the fact that such an action was not approved by the UN and has, as a result, caused some disputes within the Alliance.

In other texts, it is possible to find different anti-NATO stances. Thus, NATO aims are presented as far from clear. According to these texts, the Alliance offers few specific details. While NATO's air-raids are labelled as an increasingly desperate attempt, causing disastrous mistakes, a sense of desperation, growing fear/worries, frustration within the Alliance and civilian carnage, leading NATO to a strategic stalemate. Most of these elements on the micro level are noun phrases and they clearly point to a criticism of NATO coming from journalists. Here are some examples from the Guardian:

"There is a sense of desperation among NATO officials..." (G. Apr 1)

"Under growing pressure to demonstrate concrete results, NATO's military spokesman in Brussels has become less forthcoming about military operations." (G. Apr 1)

An explicit evaluation is obvious in the following example:

"After reciting a bitter litany of agreements betrayed..." (G, Mar 24)

This example refers to a speech of Tony Blair, the then British Prime Minister, whose aim is to justify the beginning of NATO air-strikes on Yugoslavia. The speech of the Prime Minister is referred to as a bitter litany of agreements betrayed. It is preceded by the verb recite that could be also interpreted as ironical. This position of the Guardian is, if not negative, definitely cautious regarding Blair's intentions.

On the other hand, there are journalists who openly express their anti-Serb stances. Thus, they say that the Serbs are perpetrators of mass killings, berserk warriors and rogue elements, that they terrorize the civilian population into flight and that they carry out the worst massacres, mass killings, ethnic separation and expulsion and merciless slaughter. The activities of the Serbian forces are even seen as killing spree and the activities on the field testify of the fury of the Serb forces. All these phrases are clear signals of evaluation in the news.

A paper dealing with the situation in Kosovo during the NATO airstrikes on Yugoslavia (Lakić, 2018: 202-203) discusses the use of various elements on the micro level to achieve a specific goal: "On the micro level, verbs, nouns and noun phrases mainly describe the Serbian forces and adjectives are mostly used to describe the condition of Albanian refugees. The two sides are represented blackand-white, the Serbs as active perpetrators of atrocities, and the Kosovar refugees are passive victims." With explicit units on the micro level, these examples represent presence of explicit evaluation in texts.

Logos et Littera: Journal of Interdisciplinary Approaches to Text 
In addition, the examples above show that a ready-made list of evaluators is practically impossible to make as the context imposes a specific selection of language units on the micro-level.

We can now move to less explicit and implicit presence of Evaluation in text. We will first look into the option (1) when two parts of a macrostructure are combined into one sentence or a shorter paragraph, where both parts are given equal importance. Let us consider the following example from the Guardian:

"NATO has so far emerged from the conflict almost unscathed, but last night the US army confirmed that one of its unmanned reconnaissance aircraft had been lost." (G, Apr 8)

This example is a compound sentence where the first clause is Evaluation, while the second sentence is an indirect Verbal Comment. The adverb phrase so far leads to the conclusion that NATO has been almost unscathed in the conflict, but that it is not the case anymore, which is confirmed by the second clause. However, the two clauses here have an equal role and can therefore be treated as a combination of two parts of macrostructure - Evaluation and Verbal Comment.

Evaluation is also combined with Verbal Comment in the following example:

"Although NATO claims 'air superiority' over Yugoslavia, Sir Charles Guthrie, chief of the defence staff, acknowledged yesterday that air defence systems which include hand-held anti-aircraft missiles easy to disperse and hide still pose a threat to NATO planes." (G, Apr 20, p. 2)

The first part of the sentence, i.e. the dependent clause, is an example of Evaluation, although it does not seem to be the case at first glance. However, the noun phrase air superiority put between inverted commas points to an ironical stance of the journalist regarding NATO offensive. The remaining part of the sentence is a Verbal Comment.

Another option is (2) when one part of a macrostructure is embedded into another, whereby the embedded part is usually shorter and of less formal importance, although it can cause a change in the point of view expressed in the text. Here is an example from the Independent. The Main Event starts as follows:

"NATO aircraft and warships finally launched their long-awaited air offensive..." (I, Mar 25)

With the adverb finally and the adjective phrase long-awaited the journalist sends a message that can be interpreted as a support to the NATO campaign. Thus, although the purpose of this part is to present the Main Event, there are obvious elements in the sentence that point to the presence of Evaluation. This is an example of option (2), where one part of a macrostructure (Evaluation) is embedded into another (Main Event). In addition, although the embedded part is given less space, it definitely changes the tone of the sentence, shifting the emphasis from the launch of an air offensive to the support given by the author for such an action. Thus, the 
sentence that would be expected to inform the readers about a NATO air offensive gains an additional element of Evaluation. Without the two elements, the sentence would have a neutral stance and would be a straightforward example of the Main Event.

Another example is a statement of George Robertson, the British Minister of Defence at the time:

"We are now concentrating our attention on the specific groups of people who are terrorising, who are obliterating villages, torturing and maiming." (G, Mar 29)

Formally, this sentence represents Verbal Comments. However, the verbs terrorise, obliterate, torture and maim refer to the opposing side - the Serbs. Thus, this example illustrates a presence of Evaluation even within Verbal Comments. We do not know, though, whether the journalist approves of such verbs, but implicit Evaluation is definitely present. The next paragraph in this text contains the words of a NATO general who says that the military campaign will be stepped up, broadened and intensified. It seems that putting three or four verbs in a row is used to strengthen the effect of the actions undertaken in this conflict.

The third option covers the situation in which (3) a certain part of the text can be interpreted in two ways. For example, Headlines may often express attitudes of journalists. In such a situation, Headline can be interpreted as an Evaluation at the same time, although there are no explicit linguistic means that clearly point to the existence of Evaluation. My research shows that such combinations usually include Evaluation, probably because in wartime journalists try to avoid expressing their opinions openly. Instead, they express their ideas in a less direct form, mainly through Headlines, Leads or Verbal Comments.

Indicative of this kind of combination is the article "Two Serb jets shot down over no-fly zone", published on March 27 in the Times, which reports that the Serbian planes were shot down five miles within the Bosnian territory but the pilots had not been caught. It is interesting that the paper published a statement of Yugoslav foreign minister who denied that the planes had been shot down, adding that NATO had made up the story to cover up their own losses.

The same day the Times published another article on shooting down of an American Stealth fighter.

Headline: "Stealth fighter 'shot down' as Serb slaughter hundreds"

Lead: "Bombers target Serb army units. NATO tries to halt Kosovo exodus." (T, Mar 27)

It is possible to notice immediately two interesting things in the Headline. First, in the second article, shot down is put under inverted commas, which implies that it was not a pleasant information for NATO or even that it may not have been shot actually. In addition, the second half of the Headline ("as Serbs slaughter hundreds") immediately turns the attention of the readers from shooting down of 
the Stealth to the action (slaughter) carried out by the Serbs. This is certainly an implicit Evaluation by the journalist.

Actually, both texts start with the information on shooting down the enemy's planes. However, the news about shooting down of the Serbian planes was put already in the Lead, but it looks like the first paragraph of the body of the article, because the real introductory paragraph does not repeat the information in the form of the Main Event, but starts with the Pentagon spokesperson's statement that the Yugoslav planes had been shot by American fighters. On the other hand, shooting down of the American Stealth was presented as the Main Event, in the first paragraph, in a text without Lead. What is much more striking, though, is the way in which the two pieces of information were presented.

The information on shooting down of two Serbian planes reads as follows (Lead):

"NATO aircraft yesterday shot down two Serb MiG29s after they flew into the United Nations no-fly zone over Bosnia."

The information on shooting down of the American Stealth was reported in the first paragraph as the Main Event, as follows:

"An American stealth fighter was reported to have been shot down near Belgrade last night, hours after NATO announced that it would begin lowlevel bombing missions against Serbian forces in response to reports of hundreds of Albanian civilians being massacred during an all-out offensive in Kosovo."

These examples show that the two events are not reported in the same way. Obviously, the news of the Serbian planes was short, but it clearly shows that NATO can take the "credit" for shooting the planes, which is why NATO is the subject of the sentence. The verb is in active voice, while the second part of the sentence provides the reason for this action.

When reporting the shooting down of the American plane, American Stealth fighter is subject of a passive sentence. The verb shoot down is put at the end of the sentence and the verb report is put in passive. Thus, the article does not say that "the Serbian forces shot down the American Stealth fighter". The sentence continues to set the context of the action (beginning of low-level bombing missions against Serb forces), implying that the reason for shooting down was the fact that they were flying too low. The same sentence shifts the blame to the Serbian forces who massacred hundreds of Albanian citizens in Kosovo. The link between Bosnia and Kosovo is not clear in this case. The text later reports on the Serbian actions in Kosovo, neglecting the situation with the Stealth completely. This means that the journalists tried to cover up the embarrassment with the shot Stealth with the Serbian massacres in Kosovo.

In this way, the Headline, Lead and Main Event in the second text clearly contain an implicit Evaluation. There are no obvious linguistic means that would substantiate the claim that Evaluation is also hidden behind the three parts of 
macrostructure. Still, its presence is obvious in the manner the accident was reported, especially when analysed against the previous article on shooting down of Serbian planes.

Examples like this are numerous. Evaluation may also involve cases when Verbal Comments are put in less conspicuous positions in the text if they are not in favour of the cause supported by the journalist. The verbal comment is put in the text, which fulfils the technical requirement, but its position in the text indicates a certain extent of partiality of the journalist. Sometimes, the order of events is presented in a way which favours the side supported by the journalist. In the periods of wars, media publish false information to mislead the enemy, which is also an implicit Evaluation. Media are also used to present the power and the strength of the weapons used by an army, to confound the enemy. Here is an example:

"Lancers, which can fly more than 6,000 miles without refuelling, are equipped with an array of defence systems to confound enemy radar and missiles and a new bombing system which will allow NATO to destroy Serbia armour and artillery in Kosovo without the weather and visibility problems which have hampered missions so far."

All these instances point to an implicit presence of Evaluation, without using any linguistic means to present it.

\section{Conclusion}

The presence of different parts of macrostructure in news stories is usually clear and follows some rules of journalistic profession. Still, when it comes to Evaluation, things are not that straightforward. Evaluation is the part where journalists express their opinions, attitudes or criticisms. There is abundance of descriptions in literature where Evaluation is clearly identified based on linguistic elements used to express it.

However, Evaluation is not always easy to identify, especially when no linguistic means are used to express it. That is why any attempt to produce a list of linguistic elements that point to Evaluation cannot be successful in dealing with all the situations where Evaluation appears. Each story is different and takes place in a different context, which creates various and hardly predictable linguistic possibilities of expressing one's attitude.

There are certainly cases when Evaluation is very evident and direct and these instances of explicit Evaluation are easy to cope with. The problem occurs when Evaluation is combined with other parts of macrostructure, i.e. when Evaluation appears within a sentence or paragraph next to or in combination with another part of macrostructure. However, in these instances Evaluation can still be identified based on linguistic means. The most problematic situation, though, is when Evaluation is hidden behind another part of macrostructure in a form of a meta-message. In such cases, it is possible to notice its existence only by reading "between the lines".

Logos et Littera: Journal of Interdisciplinary Approaches to Text 
Journalists resort to the latter option mainly when reporting events such as wars, accidents or disasters. These are very sensitive events that usually have a huge impact on readers, where the parameter of emotivity is the most prominent. Such situations may lead journalist to conclude that some sort of withdrawal form the story is the best position, especially if there is a danger that readers may evaluate their propositions as unreliable. This may be the reasons why Evaluation in such texts is mainly indirect or implicit.

Additional research on this issue can certainly identify many possible nuances of Evaluation and create a basis for a more consistent method in researching this part of macrostructure.

\section{References}

Bell, Alan. The Language of News Media. Oxford: Blackwell, 1994.

Bell, Alan and Garret, Peter (eds.). Approaches to Media Discourse. Oxford: Blackwell, 1998.

Bednarek, Monika. Evaluation in Media Discourse: Analysis of a Newspaper Corpus, New York, London: Continuum, 2006.

Curran, James and Seaton, Jean. Power Without Responsibility. London: Routledge, 1997.

Fairclough, Norman. Language and Power. London: Longman, 1989.

Fairclough, Norman. Media Discourse. London: Edward Arnold, 1995a.

Fairclough, Norman. Critical Discourse Analysis, the Critical Study of Language. New York: Longman, 1995b.

Fairclough, Norman. "Critical Analysis of Media Discourse". Media Studies: A Reader. Eds. Marris, Paul and Sue Thorntam. Edinburgh: Edinburgh University Press, 1996. 308- 325.

Fairclough, Norman and Wodak, Ruth. "Critical Discourse Analysis". Introduction to Discourse Analysis. Ed. Van Dijk, Teun. London: Sage, 1997. 258-284.

Fowler, Roger. Language in the News, Discourse and Ideology in the Press. London: Routledge, 1991.

Geoff, Peter (Ed.). The Kosovo News and Propaganda War. Vienna: International Press Institute, 1999.

Hammond, Peter (Ed.). Degraded Capability: the Media and the Kosovo Crisis. Pluto P, 2000. Hopkinson, Nicolas. War and Media. London: HMSO, 1992.

Lakić, Igor. "Media Discourse and Manipulation". Lingvističke analize. Eds. Perović Slavica and Vesna Bulatović. Podgorica: Institut za strane jezike, 2004. 85-96.

Lakić, Igor. Diskurs, mediji, rat. Podgorica: Univerzitet Crne Gore, Institut za strane jezike, 2011.

Lakić, Igor. (2019) "Constructing realities on war in print media discourse", Revue roumaine de linguistique, LXIV, 1 (2019): 99-111.

Lakić, Igor. "Portraying refugees in British print media: the case of NATO airstrikes on Yugoslavia", Círculo de Lingüística Aplicada a la Comunicación, Vol. 75 (2018): 191- 214.

Logos et Littera: Journal of Interdisciplinary Approaches to Text 
Lau, Ursula, Mohamed Seedat, and Victoria McRitchie. "Discursive Constructions of the Israel-Hezbollah War: The Strugglefor Representation“. The American Journal of Islamic Social Sciences 28:2 (2011): 1 - 33.

Marín Arrese, Isabel Juana, and Perucha Begoň Núňez "Evaluation and Engagement in Journalistic Commentary and News Reportage". Revista Alicantina de Estudios Ingleses 19 (2006): 225-248

Martin, James and Peter White. The Language of Evaluation. Appraisal in English. New York: Palgrave, 2005.

Stotensbury, Hilkka. "Evaluation in researh article abstracts in the narrative and hard sciences". Journal of English for Academic Purposes 2 (2003): 327-341.

Thompson, Geoff and Susan Hunston. "Evaluation: an introduction". Evaluation in Text. Authorial Stance and the Construction of Discourse. Eds. Hunston, Susan and Geoff Thompson. Oxford: Oxford University Press, 2000.

Van Dijk, Teun. "Structure of News in the Press". Discourse and Communication. Ed. Van Dijk, Teun. Berlina: De Gruyter, 1985. 60 - 93.

Van Dijk, Teun. News as Discourse. Hillsdale, NJ: Lawrence Erlbaum, 1988a.

Van Dijk, Teun. News Analysis. Hillsdale, NJ: Lawrence Erlbaum, 1988b.

Wodak, Ruth and Busch, Brigitta. Approaches to Media Texts. In:) The Sage handbook of media studies. Downing, John (Ed.). London: Sage, 2004. 105123.

Zoltán, Kiszely. "Media Discourse from a Contrastive Rhetoric Perspective". Novelty. 8(3) (2001): 4-26. 